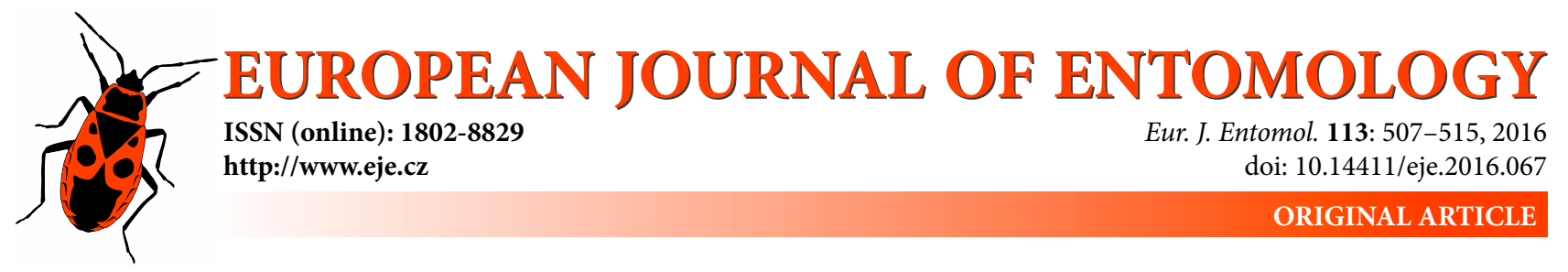

\title{
Allelic variants of cytochrome P450 monooxygenases: Constitutive and insecticide-mediated expression in a Malaysian strain of the dengue vector, Aedes aegypti (Diptera: Culicidae)
}

\author{
Fatma M.A. EL-GARJ, Mustafa F.F. WAJIDI and Silas W. AVICOR* \\ Molecular Entomology Research Group, School of Distance Education, Universiti Sains Malaysia, 11800 Minden, Penang, \\ Malaysia; e-mails: fatmagorj@yahoo.com,mfadzil@usm.my, swavicor@usm.my/wintuma@live.com
}

Key words. Diptera, Culicidae, Aedes aegypti, cytochrome P450s, structure prediction, mRNA expression, insecticide

\begin{abstract}
Cytochrome P450s (P450s) involved in insecticide resistance reduce the efficacy of insecticide-based vector control by rendering vector control ineffective. They are recorded in many species of vectors and have various constitutive and insecticide induction profiles. In this study, the isolation and prediction of the structure of a P450 from a strain of Aedes aegypti originating from Malaysia is reported. Quantitative mRNA expression of this gene and a previously reported P450, CYP4H28v2, in the developmental stages of the mosquito after exposure to sub-lethal concentrations of insecticides is also reported. The isolated P450, CYP4H31v2, is an allelic variant of CYP4H31 and contains several conserved motifs of P450s. The secondary structure of the protein is mostly made up of alpha helices and random coils. The tertiary structure was generated using homology modeling and was of good quality based on structure validation using protein structure assessment tools. CYP4H28v2 and CYP4H31v2 were differentially expressed in the developmental stages of the vector, with a significantly increased expression in adult males. The genes were significantly over-expressed in larvae exposed to deltamethrin and permethrin for $6 \mathrm{~h}$. In the DDT-treated larvae, only CYP4H31v2 was significantly over-expressed after a $6 \mathrm{~h}$ exposure. Under-expression of the genes was predominant in larvae treated with the organophosphates malathion and temephos. Though the functions of these P450s are unknown, their response to induction by exposure to insecticides indicates the likely involvement of these genes in insecticide tolerance.
\end{abstract}

\section{INTRODUCTION}

Viruses transmitted by Aedes mosquitoes are among the most devastating arboviruses affecting human health, causing morbidity and mortality in many countries. These mosquitoes are responsible for diseases like chikungunya and dengue fever. Though an integrated vector management approach is practiced in many parts of the world, a dependency on conventional insecticides is the most common means of controlling mosquito-borne diseases (van den Berg et al., 2012). However, resistance to these chemicals is reported (Vontas et al., 2012; Ishak et al., 2015). The extensive development of insecticide resistance has necessitated the inclusion of insecticide resistance management as an integral part of mosquito control. This is aimed at monitoring the resistance status of mosquito populations to detect incipient resistance and also manage resistance in populations where it is present.

The first report of dengue in Malaysia was in Penang in the 1900s (Skae, 1902), but as reported in Mudin (2014), the first recorded outbreak in Malaysia was in 1962 in Penang, resulting in 41 cases and 5 deaths. Since then several outbreaks have occurred with the worst occurring recently in 2014, with 108,698 cases and 215 deaths, more than double the mortality (92) in 2013 (Mudin, 2014). Aedes aegypti is the primary vector of dengue in Malaysia and like other parts of the world, several vector control methods are used (Lee et al., 2014), with adulticidal and larvicidal chemical compounds used extensively. Globally and nationally, the mosquito is known to have developed resistance to the major insecticide classes used for its control (Vontas et al., 2012; Ishak et al., 2015). Common insecticide resistance mechanisms include mutation of target-site proteins and detoxification of insecticides by metabolic enzymes such as cytochrome P450 monooxygenases (P450s) (Feyereisen, 2012; Vontas et al., 2012).

Over-expression of P450s has sometimes been linked to insecticide resistance in many species of mosquitoes (Amenya et al., 2008; Poupardin et al., 2010; Liu et al., 2011). In addition to insecticide detoxification, P450s metabolize a panoply of endogenous and exogenous substances and mediate a diverse range of activities in insects in the process (Feyereisen, 2012). P450s belong to several fami-

\footnotetext{
* Corresponding author; e-mails: swavicor@usm.my / wintuma@live.com
} 
lies (Feyereisen, 2012), with families 4, 6 and 9 usually implicated in insecticide resistance (Amenya et al., 2008; Poupardin et al., 2010; Gong et al., 2013). The induction of P450s by insecticides is an approach commonly used to identify P450 genes potentially involved in mediating insecticide resistance (Poupardin et al., 2010; Feyereisen, 2012). Though insecticides are widely used in Malaysia, there is a paucity of information about their effects on the P450 genes of $A$. aegypti. The status of $A$. aegypti as a major vector of diseases and the extensive use of insecticides to control it emphasizes the importance of studying insecticide-responsive P450s in this mosquito as a first step towards identifying putative insecticide-mediating P450s. This study investigated family $4 \mathrm{P} 450 \mathrm{~s}$ in a Malaysian strain of $A$. aegypti by isolating a $\mathrm{P} 450 \mathrm{cDNA}$ and profiling expression levels of this gene and another $\mathrm{P} 450$ gene (CYP4H28v2) (Elgarj \& Wajidi, 2013) in the different life stages of this mosquito and in those exposed to sub-lethal concentrations of larvicides. Though CYP4H28v2 has been isolated (Elgarj \& Wajidi, 2013), its expression profile in the different life stages of this mosquito and in response to insecticides has not yet been determined.

\section{MATERIAL AND METHODS}

\section{Mosquito colony}

The mosquitoes used in this study were subcultured at $27 \pm 2{ }^{\circ} \mathrm{C}$ and $80 \pm 10 \%$ relative humidity (El-Garj et al., 2015) from a laboratory colony of $A$. aegypti, which originated from the Malaysian state of Penang in the 1980s and reared since then at the Vector Control Research Unit (VCRU) of Universiti Sains Malaysia during which time they were not exposed to insecticides. Fourth instar larvae were used for the experiments unless stated otherwise.

\section{RNA isolation, cDNA synthesis, polymerase chain reaction (PCR) and cloning}

RNA was isolated from the larvae $(0.25 \mathrm{~g})$ using the phenolchloroform method (Jowett, 1986). cDNA was synthesized from the RNA $(5 \mu \mathrm{g})$ using a RevertAid ${ }^{\mathrm{TM}}$ Premium First Strand cDNA Synthesis Kit $\left(\right.$ Fermentas $\left.^{\circledR}\right)$. The use of commercial kits in this study followed the manufacturers' instructions unless stated otherwise. Forward (F001) and reverse (R459) primers based on the heme binding region (FXXGXXXCXG) of a partial length P450 sequence of $A$. aegypti (GenBank accession no. AY205085.1) (Elgarj \& Wajidi, 2013) were used in a PCR (Table 1) containing $1 \times$ OneTaq ${ }^{\circledR}$ Hot Start Master Mix with Standard Buffer (New England Biolabs $\left.{ }^{\circledR}\right), 0.2 \mu \mathrm{M}$ of each primer, $0.4 \mu \mathrm{g}$ cDNA and deionized water to amplify $\mathrm{P} 450$ fragments. The PCR products were separated on a $1 \%$ agarose gel and purified using Wizard ${ }^{\mathbb{}}$ SV Gel and PCR Clean-Up System (Promega ${ }^{\circledR}$ ). The purified products were ligated into pGEM ${ }^{\circledR}$-T Easy Vector $\left(\right.$ Promega $\left.^{\circledR}\right)$ and transformed into Escherichia coli JM 109 using $1 \times$ Transformation and Storage Solution (TSS) (Chung et al., 1989) as described below. The media used were Luria-Bertani (LB) agar $(20 \mathrm{~g} / \mathrm{l})$ and LB broth $(35 \mathrm{~g} / \mathrm{l})$. Single colonies of $E$. coli were inoculated into the LB broth and incubated overnight at $37^{\circ} \mathrm{C}$ and $180 \mathrm{rpm}$. The overnight culture was used to inoculate freshly prepared LB broth at a ratio of $1: 100$ and incubated $\left(37^{\circ} \mathrm{C}\right.$ and $\left.180 \mathrm{rpm}\right)$ for about $2 \mathrm{~h}$ or until the $E$. coli cells were growing exponentially and the $\mathrm{OD}_{600}=0.6$. The cells were centrifuged at $12,000 \mathrm{~g}$ for $1 \mathrm{~min}$ and the pellet placed on ice for $5 \mathrm{~min}$. The pellet was resuspended in $1 \times$ TSS, which was placed on ice for $30 \mathrm{~min}$, after which the ligation product $(5 \mu \mathrm{l})$ was added, followed by a further period on ice of $30 \mathrm{~min}$. The mixture was subjected to a heat shock at $42^{\circ} \mathrm{C}$ for $2 \mathrm{~min}$ and then placed on ice for $10 \mathrm{~min}$. It was incubated $\left(37^{\circ} \mathrm{C}\right.$ and $180 \mathrm{rpm})$ in LB broth $(600 \mu \mathrm{l})$ for $2 \mathrm{~h}$ and then centrifuged at $12,000 \mathrm{~g}$ for $1 \mathrm{~min}$. The pellet was resuspended in LB broth (50 $\mu 1)$, plated on LB agar supplemented with $100 \mu \mathrm{g} / \mathrm{ml}$ ampicillin, $40 \mu \mathrm{g} / \mathrm{ml} \mathrm{X-gal} \mathrm{and} 0.5 \mathrm{mM}$ IPTG and incubated overnight at $37^{\circ} \mathrm{C}$. Plasmid isolation was done using Wizard ${ }^{\circledR}$ Plus SV Minipreps DNA Purification System (Promega ${ }^{\circledR}$ ) and sequenced using the universal primers $\mathrm{pUC} / \mathrm{M} 13$ forward, $\mathrm{pUC} / \mathrm{M} 13$ reverse, SP6 and T7 (First Base Laboratories Sdn. Bhd.).

\section{Rapid Amplification of cDNA Ends (RACE)}

Gene-specific primers (Table 1) for 3'- and 5'-RACE were designed based on the partial nucleotide sequences of the cloned fragments. 3'-RACE PCR (Table 1) solution contained $0.2 \mu \mathrm{M}$ of each primer [SGP1 and Oligo $(\mathrm{dT})_{25} \mathrm{~V}$ ], $0.4 \mu \mathrm{g}$ cDNA, $1 \times$ OneTaq Hot Start Master Mix with Standard Buffer and deionized water in a reaction volume of $25 \mu \mathrm{l}$. The products were used in a nested PCR with similar constituents and conditions except for substituting SGP2 for SGP1. The products were analyzed on an agarose gel, purified, cloned and sequenced as described above. 5'-RACE ready cDNA and PCR were performed using SMARTer ${ }^{\text {TM }}$ RACE cDNA Amplification Kit $\left(\right.$ Clontech $\left.^{\circledR}\right)$ and Advantage ${ }^{\circledR}$ GC 2 PCR Kit $\left(\right.$ Clontech $\left.^{\circledR}\right)$. The PCR (Table 1) solution was prepared by adding $1 \times$ Advantage GC 2 PCR Buffer, $0.5 \mathrm{M}$ GC-Melt, $1 \times$ dNTP Mix, $1 \times$ Universal Primer A Mix (UPM) and $0.2 \mu \mathrm{M}$ primer specific gene (SGPR), $1.25 \mu \mathrm{g}$ 5'-RACE cDNA, $1 \times$ Advantage GC 2 Polymerase Mix and PCR-grade deionized water. The products were purified, cloned and sequenced.

\section{Isolation of full-length gene}

cDNA was synthesized from RNA as described earlier and used with primers designed using the RACE PCR products in a PCR (Table 1) using Advantage ${ }^{\circledR}$ GC 2 PCR Kit $\left(\right.$ Clontech $\left.^{\circledR}\right)$ to amplify the full-length of the gene. The products were purified, cloned and sequenced.

\section{Protein structure}

Structure characterization was done by analyzing the secondary and tertiary structures of the protein. PSIPRED v3.3 (http:// bioinf.cs.ucl.ac.uk/psipred/) and GOR IV (https://npsa-prabi. ibcp.fr/cgi-bin/npsa_automat.pl?page=/NPSA/npsa_gor4.html) were used to predict the secondary structure of the P450s. The three-dimensional (3D) structure was generated by homology modeling using SWISS-MODEL (Biasini et al., 2014). The structure was validated using PROCHECK (Laskowski et al., 1993) and ProSA-web (Wiederstein \& Sippl, 2007).

\section{Constitutive and insecticide-mediated expression}

\section{Mosquito samples for constitutive expression}

Larval ( $1^{\text {st }}-4^{\text {th }}$ instar) and adult stages were used to determine the basal expression of the P450s in these life stages. The adult mosquitoes were 3 days old and non-blood fed.

\section{Insecticide treatment}

Insecticide solutions were obtained from the VCRU, a WHO Collaborating Center for the supply of insecticide resistance test kits. Concentrations and induction periods that induced $<5 \%$ mortality in the $4^{\text {th }}$ instar larvae were used. The larvae were treated with deltamethrin $(0.01 \mathrm{ppm})$, dichlorodiphenyltrichloroethane (DDT) (4 ppm), malathion (0.0003125 ppm), temephos $(0.0000625 \mathrm{ppm})$ and permethrin $(0.05 \mathrm{ppm})$ by placing larvae (25) in a paper cup containing $100 \mathrm{ml}$ of distilled water and the respective insecticide at the required final concentration. The paper cups were maintained at a room temperature of $25 \pm 2^{\circ} \mathrm{C}$. Controls were larvae kept in insecticide-free distilled water. There 
Table 1. Primers and thermal conditions used for PCR and qPCR.

\begin{tabular}{|c|c|c|c|}
\hline Purpose & Primer name & Sequence of primer & Thermal condition \\
\hline $\begin{array}{l}\text { Partial } \\
\text { length }\end{array}$ & $\begin{array}{l}\text { F001 } \\
\text { R459 }\end{array}$ & $\begin{array}{l}\text { 5'-GATACGTTCATGTTTGAGGGGCA-3' } \\
\text { 5'-GCGATCTTTTGGCCTATGC-3' }\end{array}$ & $\begin{array}{l}94^{\circ} \mathrm{C} \text { for } 5 \mathrm{~min}, 7 \text { cycles of } 94^{\circ} \mathrm{C} \text { for } 30 \mathrm{~s}, 43^{\circ} \mathrm{C} \text { for } 30 \mathrm{~s} \\
\text { and } 72^{\circ} \mathrm{C} \text { for } 1 \mathrm{~min}, 27 \text { cycles of } 94^{\circ} \mathrm{C} \text { for } 30 \mathrm{~s}, 54^{\circ} \mathrm{C} \\
\text { for } 30 \mathrm{~s} \text { and } 72^{\circ} \mathrm{C} \text { for } 1 \mathrm{~min} \text { and finally } 72^{\circ} \mathrm{C} \text { for } 10 \mathrm{~min}\end{array}$ \\
\hline 3'-RACE & $\begin{array}{l}\text { SGP1 } \\
\text { SGP2 } \\
\text { Oligo }(d T)_{25} V\end{array}$ & $\begin{array}{l}\text { 5'-GTTTGAGGGGCACGATACGACCA-3' } \\
\text { 5'-ATTTACTTCTCGTTGATGGCC-3' } \\
\text { 5'-TTTTTTTTTTTTTTTTTTTTTTTTTGCA-3' }\end{array}$ & $\begin{array}{l}94^{\circ} \mathrm{C} \text { for } 5 \mathrm{~min}, 7 \text { cycles of } 94^{\circ} \mathrm{C} \text { for } 30 \mathrm{~s}, 43^{\circ} \mathrm{C} \text { for } 30 \mathrm{~s} \\
\text { and } 72^{\circ} \mathrm{C} \text { for } 1 \mathrm{~min}, 27 \text { cycles of } 94^{\circ} \mathrm{C} \text { for } 30 \mathrm{~s}, 51.5^{\circ} \mathrm{C} \\
\text { for } 30 \mathrm{~s} \text { and } 72^{\circ} \mathrm{C} \text { for } 1 \mathrm{~min} \text { and finally } 72^{\circ} \mathrm{C} \text { for } 10 \mathrm{~min}\end{array}$ \\
\hline \multirow[b]{2}{*}{ 5'-RACE } & \multirow{2}{*}{$\begin{array}{l}\text { SGPR } \\
\text { UPM } \\
\text { (from kit) }\end{array}$} & 5'-TTCATCGTAAAGTTTGTCTTGT-3' & \multirow{2}{*}{$\begin{array}{c}5 \text { cycles of } 94^{\circ} \mathrm{C} \text { for } 30 \mathrm{~s} \text { and } 72^{\circ} \mathrm{C} \text { for } 3 \mathrm{~min}, 5 \text { cycles } \\
\text { of } 94^{\circ} \mathrm{C} \text { for } 30 \mathrm{~s}, 68^{\circ} \mathrm{C} \text { for } 30 \mathrm{~s} \text { and } 72^{\circ} \mathrm{C} \text { for } 3 \mathrm{~min} \\
\text { and } 30 \text { cycles of } 94^{\circ} \mathrm{C} \text { for } 30 \mathrm{~s}, 66^{\circ} \mathrm{C} \text { for } 30 \mathrm{~s} \\
\text { and finally } 72^{\circ} \mathrm{C} \text { for } 3 \mathrm{~min}\end{array}$} \\
\hline & & $\begin{array}{l}\text { 5'-CTAATACGACTCACTATAGGGCAAGC } \\
\text { AGTGGCAGTGGTATCAACGCAGAGT-3' }\end{array}$ & \\
\hline $\begin{array}{l}\text { Full length } \\
\text { CYP4H31v2 }\end{array}$ & $\begin{array}{l}\text { Forward } \\
\text { Reverse }\end{array}$ & $\begin{array}{l}\text { 5'-ATGTTGTTCTTGGCCATCGTAGTGGGAGC-3' } \\
\text { 5'-TTATCTGCTCTCGATTCTTAACGCCATATT-3' }\end{array}$ & $\begin{array}{l}94^{\circ} \mathrm{C} \text { for } 3 \mathrm{~min}, 30 \text { cycles of } 94^{\circ} \mathrm{C} \text { for } 20 \mathrm{~s}, 55^{\circ} \mathrm{C} \text { for } \\
20 \mathrm{~s} \text { and } 72^{\circ} \mathrm{C} \text { for } 2 \mathrm{~min} \text { and finally } 72^{\circ} \mathrm{C} \text { for } 10 \mathrm{~min}\end{array}$ \\
\hline qPCR & $\begin{array}{l}\text { rpS17 (Forward) } \\
\text { rps17 (Reverse) } \\
\text { CYP4H28v2 (Forward) } \\
\text { CYP4H28v2 (Reverse) } \\
\text { CYP4H31v2 (Forward) } \\
\text { CYP4H31v2 (Reverse) }\end{array}$ & $\begin{array}{l}\text { 5'-AGACAACTACGTGCCGGAAG-3' } \\
\text { 5'-TTGGTGACCTGGACAACGATG-3' } \\
\text { 5'-GGTTCTGCTGTCCAAGGTCAC-3' } \\
\text { 5'-GCCAACGTGCTGCTCTATCTT-3' } \\
\text { 5'-GAATGCCCAGAAGAATCCAA-3' } \\
\text { 5'-TCGATCACCGAAATTGTGAA-3' }\end{array}$ & $\begin{array}{l}95^{\circ} \mathrm{C} \text { for } 3 \mathrm{~min} \text {, followed by } 40 \text { cycles } \\
\text { of } 95^{\circ} \mathrm{C} \text { for } 15 \mathrm{~s} \text { and } 62.5^{\circ} \mathrm{C} \text { for } 30 \mathrm{~s}\end{array}$ \\
\hline
\end{tabular}

were three replicates of each treatment. Surviving larvae were collected 1, 3 and $6 \mathrm{~h}$ after inducing the expression of the P450s.

\section{Quantitative mRNA expression}

Reverse Transcription-quantitative PCR (RT-qPCR) was used to investigate the constitutive and insecticide-mediated expression of CYP4H28v2 and CYP4H31v2 in this mosquito. Total RNA was extracted from the samples (about $30 \mathrm{mg}$ each) using an RNeasy ${ }^{\circledR}$ Mini Kit $\left(\right.$ Qiagen $\left.{ }^{\circledR}\right)$ after manual homogenization using a sterile plastic pestle. The RNA was treated with DNase I (Fermentas $\left.{ }^{\circledR}\right)$ to remove possible genomic DNA contamination as follows; incubation of $1 \times$ reaction buffer with $\mathrm{MgCl}_{2}$ and $1 \mathrm{U}$ DNase I, RNase-free per $1 \mu \mathrm{g}$ RNA in a $10 \mu \mathrm{l}$ reaction volume at $37^{\circ} \mathrm{C}$ for $15 \mathrm{~min}$, then $5 \mathrm{mM}$ EDTA was added and the mixture incubated at $65^{\circ} \mathrm{C}$ for $15 \mathrm{~min}$. RNA integrity was evaluated on a $1.2 \%$ denaturing formaldehyde agarose gel by determining the 28S : 18S RNA ratio. A Nanodrop (ASP-2680) Spectrophotometer was used to measure RNA concentration and purity. RNA with a $28 \mathrm{~S}: 18 \mathrm{~S}$ ratio of $2: 1$ and purity of $1.8-2.0$ based on $\mathrm{A}_{260} /$ $\mathrm{A}_{280}$ was used to synthesize cDNA. cDNA synthesis for RT-qPCR was done using iScript ${ }^{\mathrm{TM}}$ Reverse Transcription Supermix kit $\left(\right.$ Bio-Rad $\left.^{\circledR}\right)$ with $1 \mu \mathrm{g}$ total RNA, $1 \times$ iScript $^{\mathrm{TM}}$ RT Supermix and nuclease-free water. Aedes aegypti 40S ribosomal protein S17 (rpS17) (GenBank accession no. AY927787.2) was used as the normalization gene (El-Garj et al., 2016). Primers (Table 1) (ElGarj et al., 2016) were designed using Primer3Plus (http://www. bioinformatics.nl/cgi-bin/primer3plus/primer3plus.cgi/) and analyzed for secondary structure, melting temperature and complementarity using an Oligo Calc: Oligonucleotide Properties Calculator (http://www.basic.northwestern.edu/biotools/oligocalc. $\mathrm{html})$. The expected product lengths of the genes were $214 \mathrm{bp}$ for CYP4H28v2, 186 bp for CYP4H31v2 and $117 \mathrm{bp}$ for $r p S 17$. Optimization of the primer concentration and annealing temperature were done using concentration and thermal gradients of $0.1-1$ $\mu \mathrm{M}$ and $50-65^{\circ} \mathrm{C}$, respectively. Serial dilution of cDNA was conducted to determine standard curves for calculating amplification efficiencies of the genes based on three replicates for each dilution after five intervals of time and a no-template control. Amplification efficiencies of the primers were within the acceptable range (98.7\% for $r p S 17,104.4 \%$ for CYP4H28v2 and $102.0 \%$ for CYP4H31v2) in accordance with MIQE guidelines (Bustin et al., 2009). Correlation coefficients $\left(r^{2}\right)$ and slopes derived from the standard curves were 0.994 and -3.354 (rps 17), 0.987 and -3.221 (CYP4H28v2) and 0.991 and -3.274 (CYP4H31v2).
Gene quantification was done in a CFX96 Real-Time System $\left(\right.$ Bio-Rad ${ }^{\circledR}$ ) using $0.2 \mu \mathrm{g}$ cDNA, $1 \times \mathrm{iQ}^{\mathrm{TM}}$ SYBR $^{\circledR}$ Green supermix, $0.5 \mu \mathrm{M}$ of each primer and nuclease-free water at the thermal condition specified in Table 1 . Assay specificity was assessed using a melting curve recorded from $55.0^{\circ} \mathrm{C}$ to $95.0^{\circ} \mathrm{C}$ at increments of $0.5^{\circ} \mathrm{C}$ for $5 \mathrm{~s}$. Quantification cycle $(\mathrm{Cq})$ for each reaction was determined using the CFX96 Real-Time System $\left(\right.$ Bio-Rad $\left.^{\circledR}\right)$. There were three biological replicates and three technical replicates for each sample. Fourth instar larvae and non-insecticide treated larvae ( $4^{\text {th }}$ instar) were used as calibrators for the life stage and insecticide-mediated expression, respectively. Relative expression of the genes was computed using the method of Pfaffl (2001). One-way analysis of variance with a 0.05 significance level was used to analyze the expression data. IBM SPSS 20.0 was used for the statistical analysis. Following Strode et al. (2008), a relative expression greater than or equal to 2 was considered as significantly over-expressed while less than or equal to -2 was significantly under-expressed.

\section{RESULTS}

\section{Full-length CYP4H31v2 sequence}

The isolated full-length cDNA sequence consists of 1671 nucleotides (Fig. 1) and was named by the P450 Nomenclature Committee as CYP4H31v2. It encompasses an open reading frame of 1518 nucleotides encoding 505 amino acids with a stop codon (TAA) starting at nucleotide position 1578 and was deposited in the GenBank database (accession no. KF288931). The 5'-Untranslated Region (UTR) has 62 nucleotides while the 3'-UTR has 91 nucleotides. The P450 contains the AATAAA polyadenylation signal and a poly-A tail, which is 25 nucleotides long. CYP4H31v2 contains all the characteristic features of P450s including the C-helix motif WXXXR, EXXR in the K-helix, PXXFXPXRF of the PERF region and the well recognized identifying motif of P450s, FXXGXXXCXG (Werck-Reichhart \& Feyereisen, 2000; Feyereisen, 2012). CYP4H31v2 shares protein sequence identity with many P450s including CYP4H31 (99\%), CYP4H30 (63\%), CYP $4 H 28$ (51\%) and CYP4H28v2 (51\%). 


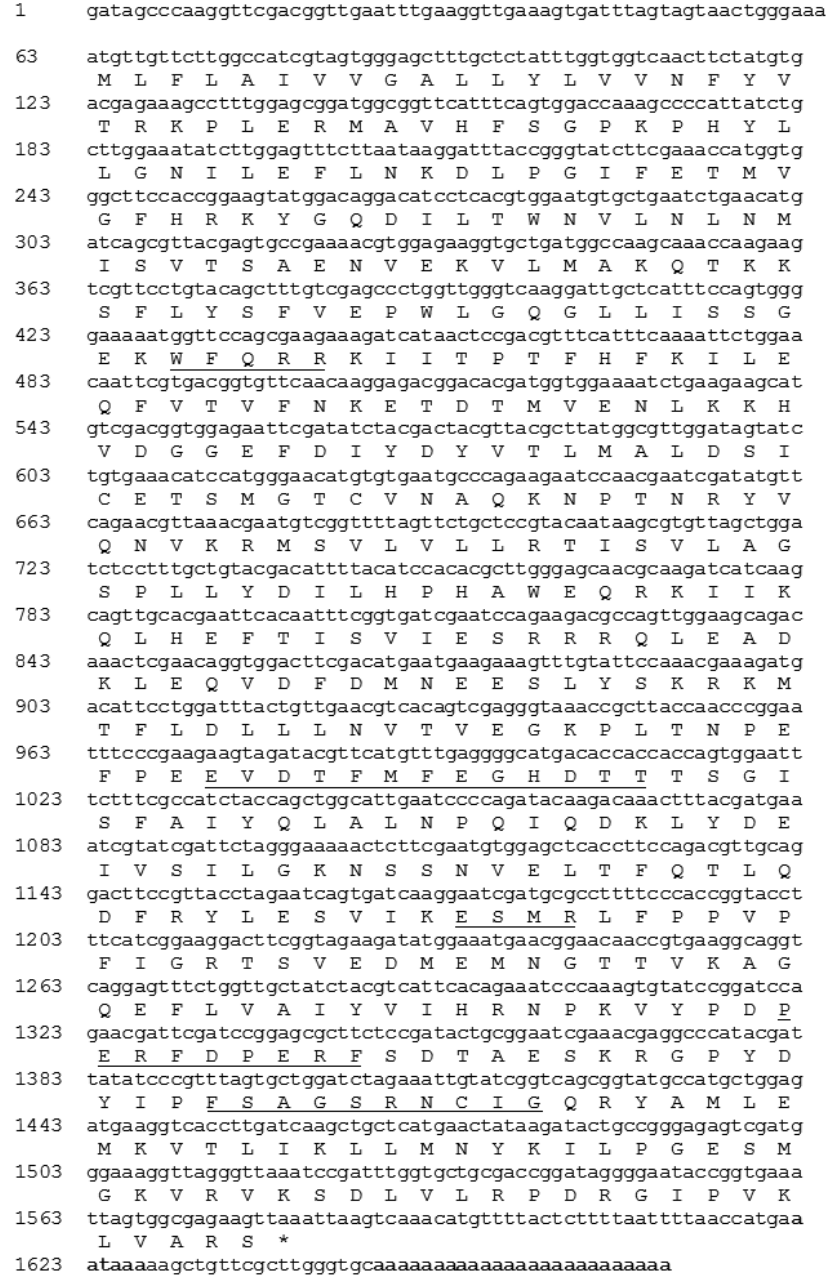

Fig. 1. Sequence of full-length CYP4H31v2 from Aedes aegypti. The sequence contains 1671 nucleotides and has an open reading frame of 505 amino acids. P450 motifs (WXXXR, EXXR, PXXFX$P X R F$ and FXXGXRXCXG) and the commonly found conserved sequence EVDTFMFEGHDTT of family 4 P450s are underlined. There are 62 and 91 nucleotides in the 5'-Untranslated Region (UTR) and 3'-UTR, respectively. The canonical polyadenylation signal AATAAA and the poly-A tail (25 nucleotides long) are in lowercase bold.

\section{Prediction of secondary and tertiary structures}

The predicted secondary structure of the protein reveals the distribution of various structural components (Fig. S1) and using GOR IV, the distribution was as follows; alpha helix $(35.25 \%)$, extended strand $(20.79 \%)$ and random coil $(43.96 \%)$. The 3D structure was generated using SWISSMODEL after template search/identification, templatetarget alignment and model building. The 3D model of CYP4H31v2 (Fig. 2) was generated using a human P450, CYP3A4 (PDB ID: 5A1P), which has a $31.22 \%$ sequence identity with CYP4H31v2 as the template. Ramachandran plot analysis indicated that $98.3 \%$ of the residues of this model were distributed within the most favored, additional allowed and generously allowed regions (Fig. S2). Analysis of the overall model quality using ProSA-web resulted in a z-score value of -7.56 (Fig. S2).

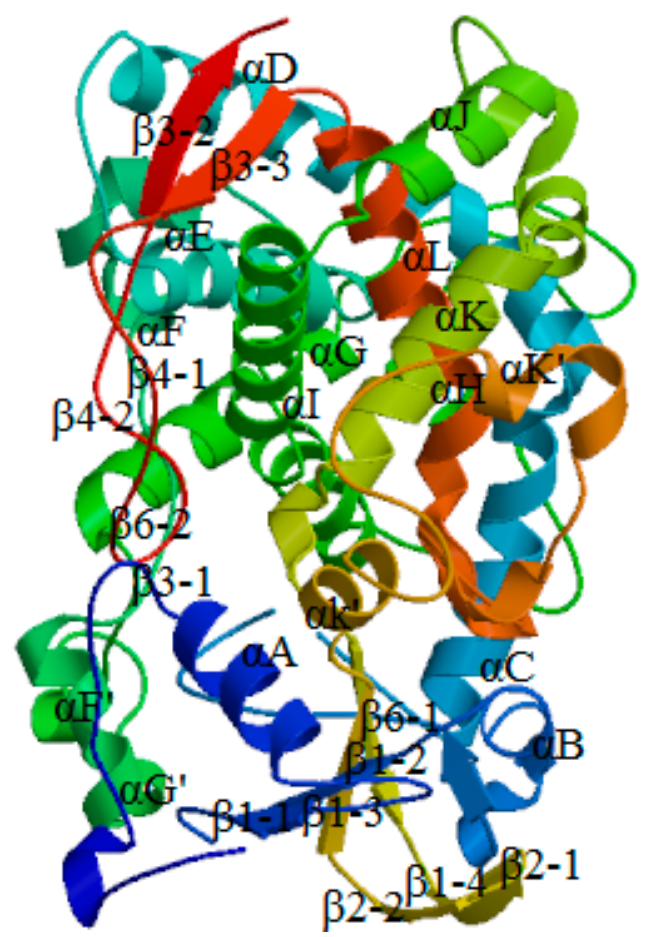

Fig. 2. Predicted tertiary structure of CYP4H31v2. Structural components are indicated on the model, with alpha helices and beta strands beginning with the prefixes $\alpha$ and $\beta$, respectively.

\section{Constitutive expression and insecticide induction of P450s}

Expression analysis of the $\mathrm{P} 450$ s revealed significant differences $(\mathrm{p}<0.05)$ between the larvae and adults of $A$. aegypti (Fig. 3). Significant over-expression of CYP4H28v2 and CYP4H31v2 were detected in the males. The larvae expressed lower levels of the P450 genes compared to the adults (Fig. 3).

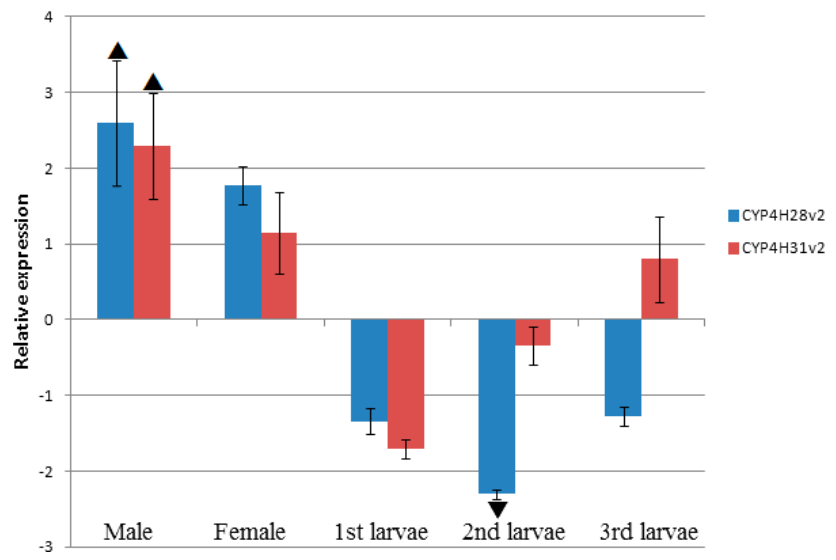

Fig. 3. Quantitative analysis of $C Y P 4 H 28 v 2$ and $C Y P 4 H 31 v 2$ in different developmental stages of Aedes aegypti $(p<0.05)$. The relative expression value is the ratio of expression in the specified developmental stage compared with that in the fourth instar larvae. Relative expression is shown as mean \pm standard error. The symbols $\boldsymbol{\Delta}$ and $\boldsymbol{\nabla}$ indicate significantly over-expressed and significantly under-expressed genes, respectively. Male: 3 day old adult male; Female: 3 day old non-blood fed adult female; 1 st larvae: 1 st instar larvae, 2nd larvae: 2 nd instar larvae; 3rd larvae: 3 rd instar larvae. 

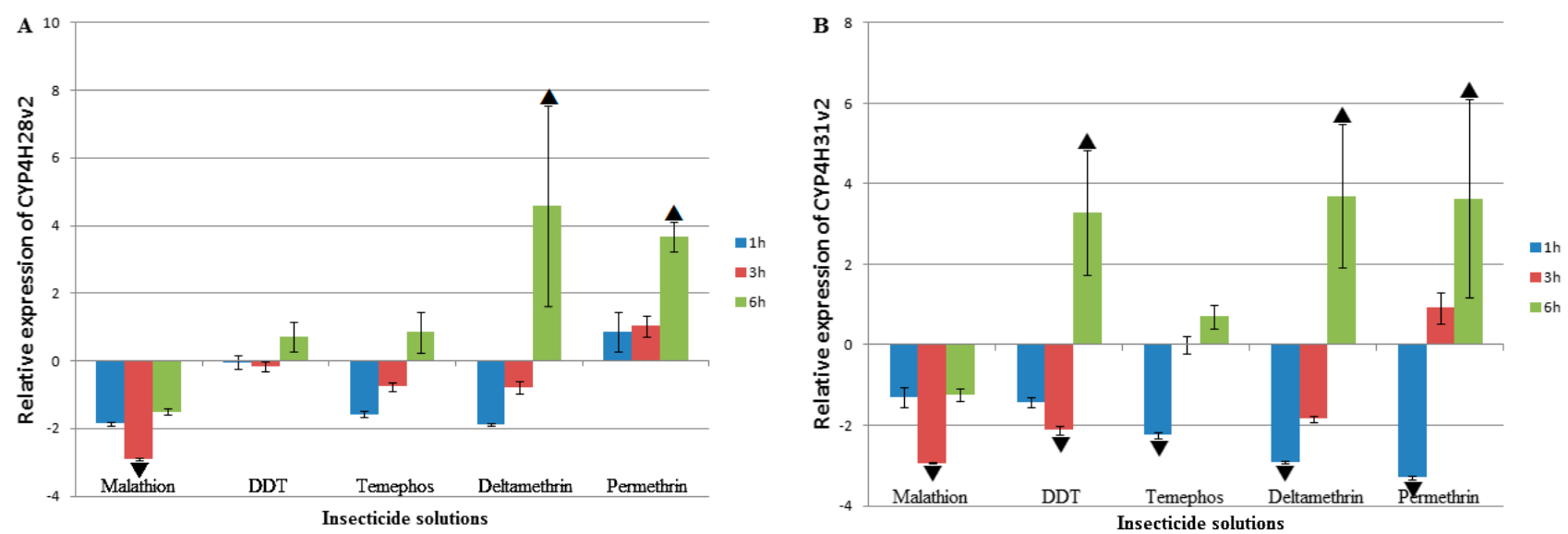

Fig. 4. Quantitative analysis of (A) CYP4H28v2 and (B) CYP4H31v2 in fourth instar larvae of Aedes aegypti after insecticide induction for different lengths of time $(p<0.05)$. The relative expression value is the ratio of expression in insecticide-induced fourth instar larvae compared to that in non-insecticide induced fourth instar larvae after a specified period of time. Relative expression is shown as mean \pm standard error. The symbols $\boldsymbol{\Delta}$ and $\boldsymbol{\nabla}$ indicate significantly over-expressed and significantly under-expressed genes, respectively.

Insecticide induction after different intervals of time revealed different expression levels of $C Y P 4 H 28 v 2$ and $C Y$ P4H31v2 in the fourth instar larvae (Fig. 4). CYP4H28v2 was not significantly increased by exposure to malathion, temephos and DDT at any of the three time intervals. In fact, malathion significantly suppressed the expression of CYP4H28v2. Deltamethrin suppressed the expression of CYP4H28v2 after $3 \mathrm{~h}$ but caused a significant over-expression of this gene after $6 \mathrm{~h}$. Permethrin induced $C Y P 4 H 28 v 2$ and this increased as the exposure time increased (Fig. 4). Significant under-expression of CYP4H31v2 was caused by the insecticides after different periods of exposure. However, significant over-expression of CYP4H31v2 was detected in larvae exposed to DDT and pyrethroids for 6 h. Exposure to DDT and deltamethrin initially suppressed the expression of $C Y P 4 H 31 v 2$ after $3 \mathrm{~h}$, but after $6 \mathrm{~h}$, the expression level increased. When exposed to permethrin, CYP4H31v2 was suppressed after $1 \mathrm{~h}$ but then its expression increased as the treatment period increased and was significantly over-expressed after $6 \mathrm{~h}$ of exposure (Fig. 4).

\section{DISCUSSION}

P450s have been extensively studied in insects as they have innumerable roles in insect development, physiology and survival (Feyereisen, 2012). Their effect on insect survival, especially by detoxifying insecticides, makes them prime candidates for insecticide resistance studies, usually revolving around identifying P450s with putative roles in insecticide resistance (Poupardin et al., 2010; Liu et al., 2011; Gong et al., 2013). Though P450s may mediate insecticide resistance in Malaysian A. aegypti (Ishak et al., 2015), neither identification of individual P450s with potential roles in insecticide resistance nor characterization of already identified P450s from other strains under insecticide-induced conditions have been conducted for Malaysian strains. This study reports the cloning of a $\mathrm{P} 450$ cDNA encoding CYP4H31v2 from the VCRU strain of $A$. aegypti. This gene is a variant of the CYP4H31 gene in the Liverpool strain. Another P450 variant, CYP4H28v2, has also been recorded in the VCRU strain (Elgarj \& Wajidi,
2013), though not much is known about it. The CYP4H28 and $C Y P 4 H 31$ genes are expressed in various proportions when exposed to permethrin and temephos in different $A$. aegypti strains (Saavedra-Rodriguez et al., 2012, 2014). Though the two A. aegypti strains are from different geographical areas, there is a very high conservation of the P450 sequences recorded for them, implying a similarity in properties and functions of the alleles from the Malaysian and Liverpool strains. However, variants of the same P450 gene could also respond differently to insecticide pressure. The genes $C Y P 6 A 5$ and $C Y P 6 A 5 v 2$ have a protein sequence identity of $99 \%$ and according to Zhu \& Liu (2008), while CYP6A5v2 was over-expressed in a pyrethroid resistant strain of house fly compared to a susceptible strain, there was no significant difference in expression of CYP6A5 in both strains. There was also a remarkable difference in the expression levels of two genes, CYP4D42v1 (3.2-fold) and CYP4D42v2 (7.0-fold) in permethrin selected Culex quinquefasciatus assessed using qPCR (Reid et al., 2012). Hence, it is important to characterize the P450 variants and determine their insecticide induction response.

Secondary structures of P450s are made up of various components (Werck-Reichhart \& Feyereisen, 2000) and in this study, alpha helices and random coils constituted the majority of the structural components of the protein, similar to the predicted secondary structure of an insect P450, CYP6AE25 (Zhang et al., 2011). However, it should be noted that the secondary structure components of $\mathrm{CY}$ $\mathrm{P} 4 \mathrm{H} 31 \mathrm{v} 2$ are computational predictions and may not be a $100 \%$ representation of the actual secondary structure of the protein. There are no crystal structures of insect P450s; hence computational models are used to generate 3D structures for insights into insect P450 structures and for further computational investigations. The $3 \mathrm{D}$ model of CYP4H31v2 has the conserved folds of P450s (Werck-Reichhart \& Feyereisen, 2000). The conserved core is made up of a bundle consisting of the helices D, E, I and L, the $\mathrm{J}$ and $\mathrm{K}$ helices, two $\beta$-sheets and the meander region (Werck-Reichhart \& Feyereisen, 2000). These structures also contain P450 motifs and the catalytic heme binding 
region of P450s (Werck-Reichhart \& Feyereisen, 2000; Feyereisen, 2012). Ramachandran plot of the CYP4H31v2 model showed that $1.7 \%$ of the residues were located in the disallowed regions. This compared favorably with residues in the disallowed regions of models of Anopheles minimus CYP6AA3, CYP6P7 and CYP6P8 and human CYP4A22, which ranged from 0.5 to $2.9 \%$ (Gajendrarao et al., 2010; Lertkiatmongkol et al., 2011). The ProSA z-score indicated that the overall quality of the model was good and comparable to the z-score of experimentally determined proteins of similar size.

Constitutive expression profiles of $\mathrm{CYP} 4 \mathrm{H} 28 \mathrm{v} 2$ and $\mathrm{CY}$ $P 4 H 31 v 2$ differed in the different developmental stages of this mosquito. The P450s were suppressed in the larvae compared to the adults. High expression of the P450s in the adult stage compared to the larval stage suggests that the genes may be involved in adult stage activities, which could include survival when exposed to adulticidal compounds. In the adults, the genes were over-expressed in the males but not the females, though a more than 1-fold expression was detected in the females. Survival by insecticide detoxification and reproduction are important activities needed for the perpetuation of a population. However, resources may be limiting for performing both tasks, hence an optimal resource allocation occurs, which is reflected in a trade-off between the competing demands of reproduction and insecticide detoxification resulting in the suppression of P450s in females (McGraw et al., 2004).

Insecticide-based vector control relies on the efficacy of the chemical agents used to control the target species (Vontas et al., 2012; Avicor et al., 2013, 2015; El-Garj et al., 2015). However, the development of resistance lowers the efficacy of insecticides and diminishes the effectiveness of insecticide-based vector control (Temu et al., 2012). Therefore, identifying P450s with putative roles in insecticide resistance is key to resistance detection and management for an effective vector control system. Insecticides can induce P450s and the over-expression of P450s in insecticide-resistant and treated strains sometimes provide cues for identifying putative insecticide detoxifying P450s (Amenya et al., 2008; Poupardin et al., 2010; Huang et al., 2013). Some studies on the induction potential of insecticides on P450s use sub-lethal concentrations as in this present study and other previous works (Poupardin et al., 2010; Avicor et al., 2014) to record the adaptive response of insects to toxic compounds. Differential expression of CYP4H28v2 and CYP4H31v2 in A. aegypti larvae in this study was dependent on the type of insecticide and exposure time. This pattern is consistent with previous studies on other insects, including species of Aedes (Poupardin et al., 2010; Liu et al., 2011; Huang et al., 2013; Avicor et al., 2014). CYP4H28v2 and CYP4H31v2 were strongly induced by permethrin after a $6 \mathrm{~h}$ exposure. A similar pattern was also recorded in larvae exposed to deltamethrin for 6 h. Pyrethroid-induced expression of the A. aegypti $\mathrm{P} 450 \mathrm{~s}$ is consistent with previous studies on $\mathrm{P} 450$ induction in pyrethroid-treated insects (Jiang et al., 2010; Poupardin et al., 2010; Liu et al., 2011; Huang et al., 2013). Significant up- regulation of $C Y P 4 H 28 v 2$ and $C Y P 4 H 31 v 2$ in this strain implies the potential involvement of both genes in pyrethroid tolerance, corroborating the suspected involvement of P450s in resistance of $A$. aegypti from this region based on synergistic assays (Ishak et al., 2015). Larvae exposed to DDT significantly expressed only CYP4H31v2 after a $6 \mathrm{~h}$ exposure. Over-expression of the genes after a longer exposure may be attributed to a delay in the response of the mosquito to the insecticide. Therefore, longer exposure could strongly induce P450s but this can also cause an inverse response as indicated in the under-expression of CYP9M8 in permethrin exposed $A$. aegypti as induction time increased from 6 to $48 \mathrm{~h}$ (Poupardin et al., 2010).

Mosquito strains vary in their capacity to express P450s in response to insecticide stress (Liu et al., 2011; SaavedraRodriguez et al., 2014) and in this study; malathion and temephos suppressed the expression of CYP4H28v2 and CYP4H31v2 in the larvae regardless of the exposure time. In a previous study (Huang et al., 2013), malathion does not over-express family $4 \mathrm{P} 450 \mathrm{~s}$ in Bactrocera dorsalis and significantly suppresses the expression of some of the genes at longer post-treatment sampling periods. SaavedraRodriguez et al. (2014) also reported the suppression of CYP4H28 and CYP4H31 in some field strains of A. aegypti following temephos treatment, similar to the results of this study, however, over-expression of the genes was also noticed in some strains in that study. Though El-Garj et al. (2016) recorded an increase in expression of CYP4H28v2 and $C Y P 4 H 31 v 2$ in adult females, which were briefly exposed to paper impregnated with DDT (4\%), malathion $(0.8 \%)$ and permethrin $(0.25 \%)$, organophosphate in the present study suppressed the expression of these genes in larvae. This could be due to the low basal levels of $C Y$ P4H28v2 and CYP4H31v2 in larvae compared to adults. Suppression of CYP4H28v2 and CYP4H31v2 in organophosphate-treated larvae in the present study is indicative of their limited effect in detoxifying these insecticides at this stage of the insect's development. It is also likely to be an adaptive response that regulates the internal system of an organism that has been altered by insecticidal stress (Morgan, 2001).

In conclusion, the cloning and characteristics of a P450 gene, $C Y P 4 H 31 v 2$, including its predicted 3D model was reported. mRNA expression profiles of $C Y P 4 H 28 v 2$ and CYP4H31v2 revealed high levels of expression of both genes in adult males. Subjecting the larvae to insecticide stress induced differential expression of the genes with significant over-expression of CYP $4 H 28 v 2$ in permethrin- and deltamethrin-treated larvae and significant over-expression of CYP4H31v2 in DDT-, permethrin- and deltamethrintreated larvae. This study highlights the potential importance of these genes in the tolerance of $A$. aegypti of the aforementioned insecticides and the need to use genetic linkage analysis and metabolism assays to understand and pinpoint their functional roles in insecticide metabolism.

ACKNOWLEDGEMENTS. This work was funded by the Malaysian Ministry of Education (ERGS 203/PJJAUH/6730097) and Universiti Sains Malaysia (RU grant 1001/PJJAUH/815095). 
The authors are grateful to the Libyan government for supporting the doctoral candidature of FMAE.

\section{REFERENCES}

Amenya D.A., Naguran R., Lo T.-C.M., Ranson H., Spillings B.L., Wood O.R., Brooke B.D., Coetzee M. \& Koekemoer L.L. 2008: Over expression of a cytochrome P450 (CYP6P9) in a major African malaria vector, Anopheles funestus, resistant to pyrethroids. - Insect Mol. Biol. 17: 19-25.

Avicor S.W., Owusu E.O. \& WaJid M.F.F. 2013: D-allethrin based mosquito coils for mosquito control: knockdown and mortality effects on the malaria vector Anopheles gambiae sensu lato. - Int. J. Agric. Biol. 15: 1035-1038.

Avicor S.W., WAJIDI M.F.F., EL-GarJ F.M.A., JAAL Z. \& YAHAYA Z.S. 2014: Insecticidal activity and expression of cytochrome P450 family 4 genes in Aedes albopictus after exposure to pyrethroid mosquito coils. - Protein J. 33: 457-464.

AvicoR S.W., WAJIDI M.F.F. \& JAAL Z. 2015: Laboratory evaluation of three commercial coil products for protection efficacy against Anopheles gambiae from southern Ghana: a preliminary study. - Trop. Biomed. 32: 386-389.

Biasini M., Bienert S., Waterhouse A., Arnold K., Studer G., Schmidt T., Kiefer F., Cassarino T.G., Bertoni M., Bordoli L. \& Schwede T. 2014: SWISS-MODEL: modelling protein tertiary and quaternary structure using evolutionary information. - Nucl. Acids Res. 42: W252-W258.

Bustin S.A., Benes V., Garson J.A., Hellemans J., Huggett J., Kubista M., Mueller R., Nolan T., Pfaffl M.W., Shipley G.L., VANDESOMPELE J. \& WitTwer C.T. 2009: The MIQE guidelines: minimum information for publication of quantitative real-time PCR experiments. - Clin. Chem. 55: 611-622.

Chung C.T., Niemela S.L. \& Miller R.H. 1989: One-step preparation of competent Escherichia coli: transformation and storage of bacterial cells in the same solution. - Proc. Natn. Acad. Sci. U.S.A. 86: 2172-2175.

Elgarj F.N.A. \& WaJIDI M.F.F. 2013: Molecular cloning and characterization a novel gene encoding CYP4H28v2 from the mosquito, Aedes aegypti. - Int. J. Chem. Environ. Biol. Sci. 1: 246-249.

El-Garj F.M.A., Avicor S.W., WaJidi M.F.F. \& JAAL Z. 2015: Comparative efficacy of spatial repellents containing d-allethrin and d-trans allethrin against the major dengue vector Aedes aegypti (Linnaeus). — Asian Biomed. 9: 313-320.

El-Garj F.M.A., Avicor S.W. \& WaJid M.F.F. 2016: Xenobioticinduced expression of detoxification genes, CYP4H28v2 and CYP4H31v2 in the dengue mosquito Aedes aegypti. - Trop. Biomed. 33: 409-419.

Feyereisen R. 2012: Insect CYP genes and P450 enzymes. In Gilbert L.I. (ed.): Insect Molecular Biology and Biochemistry. Elsevier, Oxford, pp. 236-316.

Gajendrarao P., Krishnamoorthy N., Sakkiah S., Lazar P. \& LEE K.W. 2010: Molecular modeling study on orphan human protein CYP4A22 for identification of potential ligand binding site. - J. Mol. Graph. Model. 28: 524-532.

Gong Y., Li T., Zhang L., Gao X. \& Liu N. 2013: Permethrin induction of multiple cytochrome $\mathrm{P} 450$ genes in insecticide resistant mosquitoes, Culex quinquefasciatus. - Int. J. Biol. Sci. 9: 863-871.

Huang Y., Shen G.-M., Jiang H.-B., JiAng X.-Z., Dou W. \& Wang J.-J. 2013: Multiple P450 genes: identification, tissue-specific expression and their responses to insecticide treatments in the oriental fruit fly, Bactrocera dorsalis (Hendel) (Diptera: Tephritidea). — Pestic. Biochem. Physiol. 106: 1-7.
IshaK I.H., JAAL Z., RANSON H. \& WondJI C.S. 2015: Contrasting patterns of insecticide resistance and knockdown resistance (kdr) in the dengue vectors Aedes aegypti and Aedes albopictus from Malaysia. - Parasit. Vectors 8: 181, 13 pp.

Jiang H.-B., TANG P.-A., XU Y.-Q., AN F.-M. \& WANG J.-J. 2010: Molecular characterization of two novel deltamethrin inducible P450 genes from Liposcelis bostrychophila Badonnel (Psocoptera: Liposcelididae). — Arch. Insect Biochem. Physiol. 74: $17-37$.

JowetT T. 1986: RNA extraction. In Roberts D.B. (ed.): Drosophila: A Practical Approach. IRL Press, New York, pp. 279-280.

LASKowski R.A., MacArthur M.W., Moss D.S. \& ThORnton J.M. 1993: PROCHECK - a program to check the stereochemical quality of protein structures. - J. Appl. Cryst. 26: 283-291.

Lee H.L., Rohani A., Khadri M.S., Nazni W.A., Rozilawati H., Nurulhusna A.H., Nor Afizah A.H., Roziah A., Rosilawati R. \& Tен C.H. 2014: Dengue vector control in Malaysia-challenges and recent advances. - Int. Med. J. Malaysia 14: 11-16.

Lertkiatmongkol P., Jenwitheesuk E. \& Rongnoparut P. 2011: Homology modeling of mosquito cytochrome P450 enzymes involved in pyrethroid metabolism: insights into differences in substrate selectivity. — BMC Res. Notes 4: 321, 7 pp.

Liu N., Li T., ReID W.R., YANG T. \& Zhang L. 2011: Multiple cytochrome P450 genes: their constitutive overexpression and permethrin induction in insecticide resistant mosquitoes, Culex quinquefasciatus. - PLoS ONE 6(8): e23403, 8 pp.

McGraw L.A., Gibson G., Clark A.G. \& Wolfner M.F. 2004: Genes regulated by mating, sperm, or seminal proteins in mated female Drosophila melanogaster. - Curr. Biol. 14: $1509-1514$.

Morgan E.T. 2001: Regulation of cytochrome P450 by inflammatory mediators: why and how. - Drug Metab. Dispos. 29: 207-212.

Mudin R.N. 2014: Dengue incidence and the prevention and control program in Malaysia. - Int. Med. J. Malaysia 14: 5-9.

Pfaffl M.W. 2001: A new mathematical model for relative quantification in real-time RT-PCR. - Nucl. Acids Res. 29(9): e45, $6 \mathrm{pp}$.

Poupardin R., Riaz M.A., Vontas J., David J.P. \& Reynaud S. 2010: Transcription profiling of eleven cytochrome P450s potentially involved in xenobiotic metabolism in the mosquito Aedes aegypti. - Insect Mol. Biol. 19: 185-193.

Reid W.R., Zhang L., Liu F. \& Liu N. 2012: The transcriptome profile of the mosquito Culex quinquefasciatus following permethrin selection. - PLOS ONE 7(10): e47163, 12 pp.

Saavedra-Rodriguez K., Suarez A.F., Salas I.F., Strode C., Ranson H., Hemingway J. \& Black IV W.C. 2012: Transcription of detoxification genes after permethrin selection in the mosquito Aedes aegypti. — Insect Mol. Biol. 21: 61-77.

Saavedra-Rodriguez K., Strode C., Flores A.E., Garcia-Luna S., Reyes-Solis G., Ranson H., Hemingway J. \& Black IV W.C. 2014: Differential transcription profiles in Aedes aegypti detoxification genes after temephos selection. - Insect Mol. Biol. 23: 199-215.

Skae F.M.T. 1902: Dengue fever in Penang. - Br. Med. J. 2: $1581-1582$.

Strode C., Wondji C.S., David J.-P., Hawkes N.J., Lumjuan N., Nelson D.R., Drane D.R., Karunaratne S.H.P.P., Hemingway J., BLACK IV W.C. \& RANSON H. 2008: Genomic analysis of detoxification genes in the mosquito Aedes aegypti. - Insect Biochem. Mol. Biol. 38: 113-123.

Temu E.A., Maxwell C., Munyekenye G., Howard A.F.V., Munga S., Avicor S.W., Poupardin R., Jones J.J., Allan R., Kleinschmidt I. \& Ranson H. 2012: Pyrethroid resistance in 
Anopheles gambiae, in Bomi County, Liberia, compromises malaria vector control. — PLOS ONE 7(9): e44986, 6 pp.

van den Berg H., Zaim M., Yadav R.S., Soares A., Ameneshewa B., Mnzava A., HiI J., Dash A.P. \& Ejov M. 2012: Global trends in the use of insecticides to control vector-borne diseases. Environ. Health Perspect. 120: 577-582.

Vontas J., Kioulos E., Pavlidi N., Morou E., della Torre A. \& RANSON H. 2012: Insecticide resistance in the major dengue vectors Aedes albopictus and Aedes aegypti. - Pestic. Biochem. Physiol. 104: 126-131.

Werck-Reichnart D. \& Feyereisen R. 2000: Cytochromes P450: a success story. - Genome Biol. 1(6): reviews3003, 9 pp.
Wiederstein M. \& SipPL M.J. 2007: ProSA-web: interactive web service for the recognition of errors in three-dimensional structures of proteins. - Nucl. Acids Res. 35: W407-W410.

Zhang Y.L., Kulye M., Yang F.S., Xiao L., Zhang Y.T., Zeng H., WANG J.H. \& LIU Z.X. 2011: Identification, characterization, and expression of a novel P450 gene encoding CYP6AE25 from the Asian corn borer, Ostrinia furnacalis. - J. Insect Sci. 11: $37,17 \mathrm{pp}$.

Zhu F. \& LiU N. 2008: Differential expression of CYP6A5 and CYP6A5v2 in pyrethroid-resistant house flies, Musca domestica. - Arch. Insect Biochem. Physiol. 67: 147-161.

Received April 21, 2016; revised and accepted July 18, 2016 Published online October 19, 2016

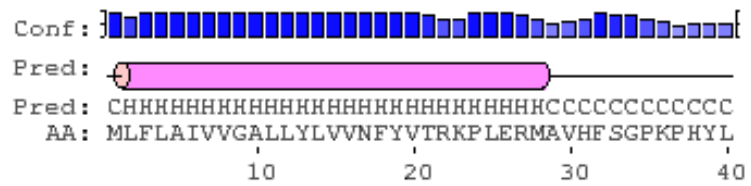

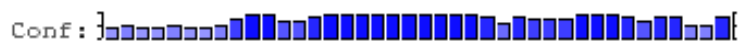

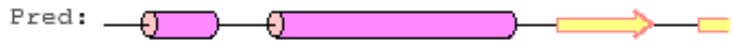

Pred: CCCHHHHCCCCHHHHHHHHHHHHHHHCCCEEEEEECCCEE AA: LGNI LEF LNKDLPG IFE TMVGF HRKYGQD I L TWNVLNLNM $\begin{array}{llll}50 & 60 & 70 & 80\end{array}$

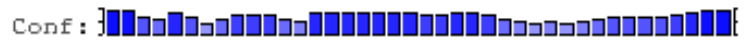

Pred:

Pred: EEECCCCHHHHHCCCCCCCCCCCCCCCCCCCCCCCCCCCC

AA: ISVTSAENVEKVLMAKQTKKSF LYSFVEPWLGDGLLISSG

90 $100 \quad$ i10

Conf : \}

Pred: $\longrightarrow$

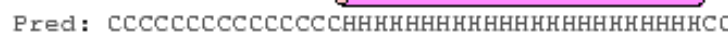

AA : EKWFQRRKI ITP TF HFK ILEQFVTVFNKE TD TMVENLKKH

$$
\text { i30 140 150 } 160
$$

Conf : \}

Pred:

Pred: CCCCCCCHHHHHHHHHHHHHHHHHCCCCCCCCCCCCCHHH AA：VDGGEFD IYDYVTLMALDSICE TSMGTCVNAQKNP TNRYV

$$
170 \quad 180 \quad 190 \quad 200
$$

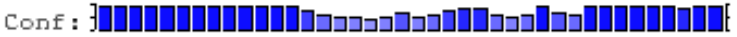

Pred:

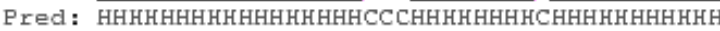
AA: QNVKRMSVLVLLRT ISVLAGSP LL YD ILHPHAWEQRKIIK

$$
\begin{array}{llll}
210 & 2 & 1 \\
& 230 & 230 & 240
\end{array}
$$

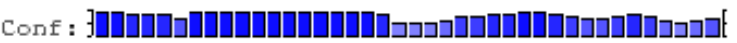

Pred:

Pred: НHнHНHнHНHнHнHНHнHНСCCCCCCCCCCCCCCCCCHH AA : QLHEFTISVIESRRRQLER.DKLEQVDF DMNEESL YSKRKM

$$
\begin{array}{llll}
250 & 260 & 270 & 280
\end{array}
$$

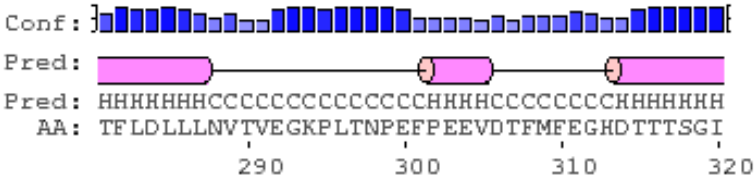

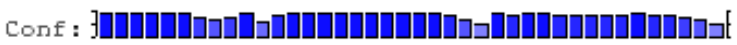
Pred: $\longrightarrow$

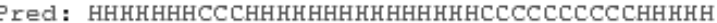

AA: SEAIYQLA.LNPQIQDKLYDEIVSILGKNSSNVELTEQTLQ $\begin{array}{llll}330 & 3 & 1 & 1 \\ 340 & 350 & 360\end{array}$
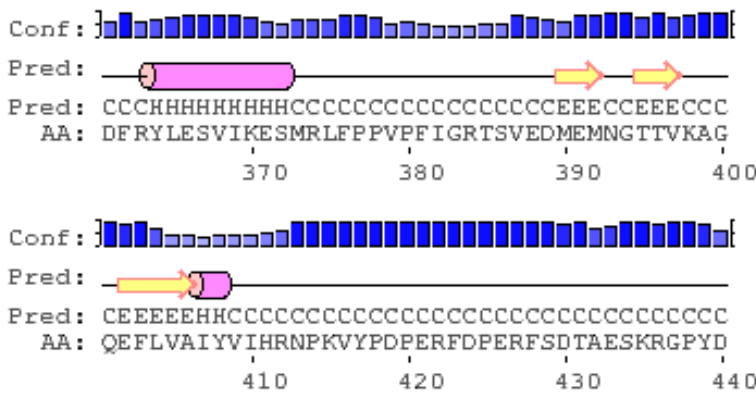

\section{Conf : $\}_{3}$}

Pred: $\underset{\text { Pred: CCCCCCCCCCHHHHHHHHHHHHHHHHHHHHHCEEECCCCC }}{\longrightarrow}$

AA: YIPFSAGSRNCIGQRYAMLEMKVT LIKLLMNYKILPGESM

$\begin{array}{llll}450 & 4 & & \\ 460 & 470 & 480\end{array}$

Conf : 30 :

Pred: $\longrightarrow \longrightarrow$

\begin{tabular}{|c|c|c|}
\hline Iegend: & & \\
\hline$\Rightarrow$ & $\begin{array}{l}\text { - helix } \\
\text { - strand }\end{array}$ & 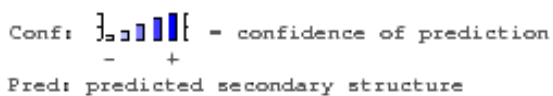 \\
\hline & $-\operatorname{coil}$ & hat target sequence \\
\hline
\end{tabular}

Pred: CCCEECCCEEECCCCCCCEEEEECC

AA: GKVRVKSDLVLRPDRGIPVKLVARS

$490 \quad 500$

Fig. S1. Predicted secondary structure of CYP4H31v2. The secondary structure was predicted using PSIPRED v3.3 (http://bioinf.cs.ucl. ac.uk/psipred/). The insert legend indicates the predicted secondary structure and confidence of prediction at each amino acid position. 


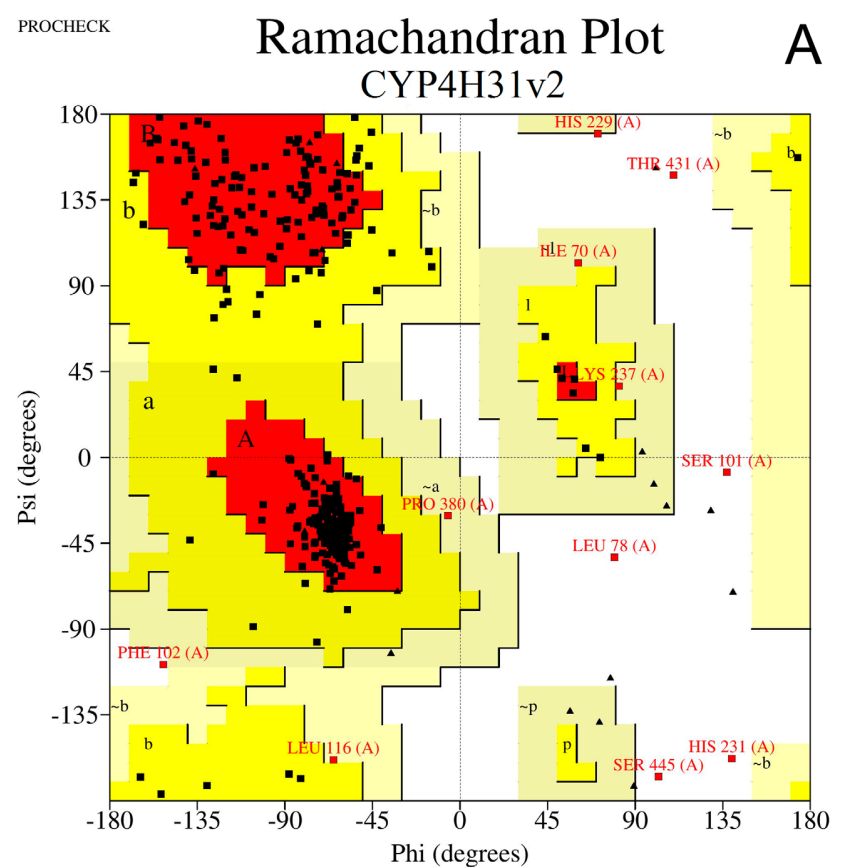

Overall model quality

Z-Score: -7.56

ProSA-web

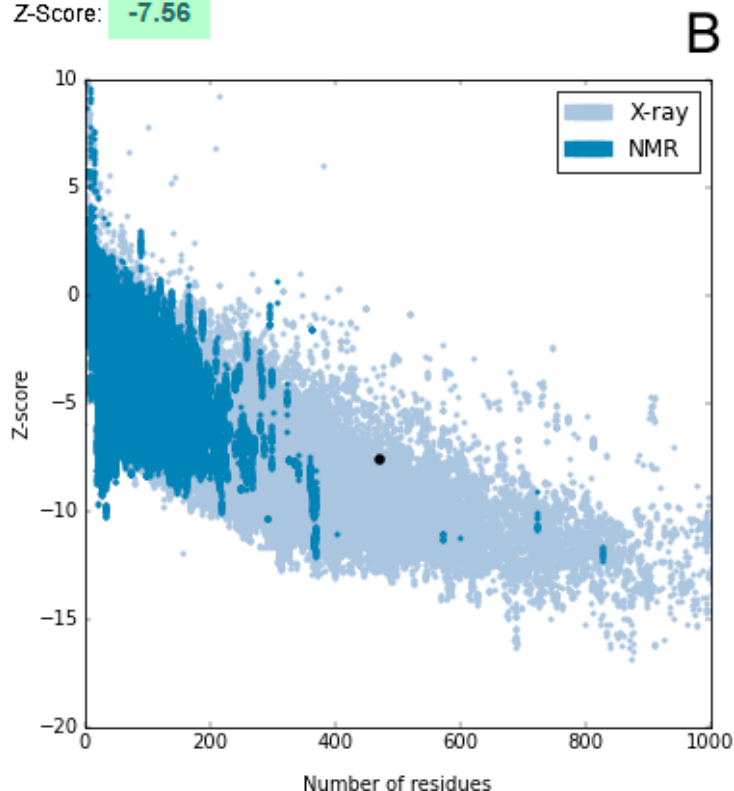

Fig. S2. Structure validation of CYP4H31v2 model. (A) Ramachandran plot analysis of CYP4H31v2 model. Red, yellow, cream and white regions are the most favored, additional allowed, generously allowed and disallowed regions, respectively. Distribution of the residues within the regions is as follows; $86.7 \%$ in the most favored regions, $10.9 \%$ in additional allowed regions, $0.7 \%$ in generously allowed regions and $1.7 \%$ in disallowed regions. (B) Z-score of $\mathrm{CYP} 4 \mathrm{H} 31 \mathrm{v} 2$ model. The $X$-axis shows the number of residues of protein structures obtained fusing X-ray or NMR while the Y-axis shows their Z-score values. Z-score of CYP4H31v2 indicates the quality of the generated CYP4H31v2 model in comparison with native proteins of similar size experimentally determined using X-ray or NMR. 